\title{
MicroRNA-194 Regulates \\ Lipopolysaccharide-Induced Cell Viability by Inactivation of Nuclear Factor- $\kappa$ B Pathway
}

Fei Xie ${ }^{a}$ Lei Yang ${ }^{b}$ Lili Hanc Bin Yue

aThe First Department of Pediatric, Cangzhou Central Hospital, Cangzhou, ${ }^{\mathrm{b}}$ The Third Department of Orthopedics, Cangzhou Central Hospital, Cangzhou, 'The First Department of Neurology, Cangzhou Central Hospital, Cangzhou, China

\section{Key Words}

MicroRNA-194 • Lipopolysaccharide • Infantile pneumonia

\begin{abstract}
:
The present study explored the functional role of microRNA (miR)-194 in lipopolysaccharide (LPS) induced lung cell injury, along with the underlying mechanisms and to reveal the potential role in infantile pneumonia. Human fibroblasts WI38 cells were transfected with miR-194 mimic or miR-194 inhibitor, and the transfection efficiency was confirmed by quantitative realtime polymerase chain reaction (qRT-PCR). Thereafter, the cells were treated with or without LPS, and then cell viability, cell apoptosis and mRNA and protein expressions of key proteins

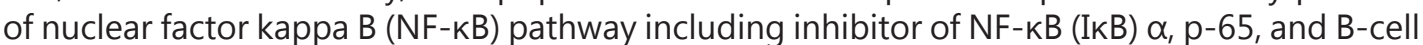
$\mathrm{CLL} /$ lymphoma $(\mathrm{BCl}) 3$ were analyzed. Results showed that overexpression and suppression of miR-194 was effective. Administration of LPS significantly decreased the cell viability and statistically promoted the percentages of apoptotic cells and increased the mRNA and protein expressions of $\mathrm{p}-65$ and $\mathrm{Bcl}-3$ but downregulated IKB $\alpha$ compared to the control group $(P<$ 0.05 or $P<0.01$ ). LPS in combination with miR-194 suppression further enhanced the effects of LPS on cell viability and cell apoptosis compared to the LPS group $(P<0.05)$. In contrast, LPS in combination with miR-194 overexpression observably reversed the effects of LPS on cell viability, cell apoptosis and mRNA and protein expressions of the key proteins $(P<0.05$ or $P<0.01)$. In conclusion, miR-194 increases the LPS-induced the inhibition of cell viability and increasing of the cell apoptosis by inhibition of NF-KB pathway in WI38 cells. MiR-194 might be a potential targeted therapy for treatment of infantile pneumonia.
\end{abstract}

\section{Introduction}

Pneumonia carries a high risk of morbidity and mortality, especially among children, causing about $23 \%$ of mortality in infants $[1,2]$. Infantile pneumonia has been ranked as 


\section{Cellular Physiology Cell Physiol Biochem 2017;43:2470-2478

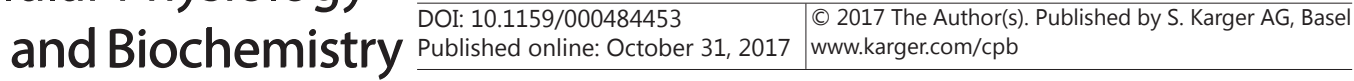 \\ Xie et al.: Potential Role of Mir-194 in Pneumonia}

one of the three most important forms of pneumonia by the World Health Organization (WHO), and it has been classified as one of four critical diseases in child health in China [3]. Approximately 4, 000, 000 children die each year due to pneumonia among $<5$ years old worldwide, particularly in developing countries $(300,000$ new deaths are observed in China every year) [3]. Bacterial infection, viral infection, and Mycoplasma pneumoniae infection are the three main causes of infantile pneumonia. Although significant advances have been made in recent years in the diagnosis and treatment of infantile pneumonia, this disease still threatens the health of many children. Thus, there is an urgent need to explore new potential targeted therapies for treatment of infantile pneumonia.

MicroRNAs (miRNAs) are small short endogenous RNAs that regulate the expression of complementary messenger RNAs (mRNAs) at the post-transcriptional level by mainly binding to the 3'-untranslated region (UTR) of target mRNAs [4, 5]. It has been well known that miRNAs play an important role in regulating various cell functions such as cell proliferation, differentiation, migration, invasion, and apoptosis [6]. A growing number of studies have confirmed that miRNAs are differentially expressed in pneumonia, and many of them have been considered as biomarkers of pneumonia [7-9]. Among the miRNAs, miR-194 has been widely studied in various cancer cells, and shows complicated functions in regulating cell differentiation [10], cell migration [11], cell proliferation, apoptosis [12], and invasion [13]. For example, Dong et al. suggested that miR-194 inhibited epithelial to mesenchymal transition (EMT) of endometrial cancer (EC) cells by targeting oncogene B-cell-specific Moloney murine leukemia virus insertion site 1 (BMI-1) and inhibition of BMI-1 by miR-194 may have therapeutic potential in suppressing EC metastasis [14]. In addition, a previous study showed that miR-194 may serve as a valuable prognostic marker and promising interventional therapeutic target for hepatocellular carcinoma (HCC) [15]. Moreover, it has been reported that miR-194 plays a significant role in chondrogenic differentiation of human Adipose-derived stem cells (ASCs), which may provide a novel insight into cell manipulation methods during cartilage regeneration [16]. However, little information is available about the role of miR-194 in regulating lung cell injury, as well as its potential functional role in infantile pneumonia.

Therefore, in the present study, we aimed to explore the functional role of miR-194 in lung cell injury and potential role in infantile pneumonia. Human lung fibroblast WI38 cells were transfected with miR-194 mimic or inhibitor, and then the cells were stimulated with lipopolysaccharide (LPS) to induce lung cell injury and inflammatory response. Thereafter, the effects of miR-194 aberrant expression on cell viability and cell apoptosis were investigated. Moreover, we explored the involved potential signalling pathway. Our study might provide new insights into potential targeted therapies for treatment of infantile pneumonia.

\section{Materials and Methods}

\section{Cell culture}

Normal human fibroblasts WI38 cell line was obtained from the American Type Culture Collection (ATCC, Manassas, VA, USA). The cells were cultured in Dulbecco's modified Eagle's medium (DMEM; SigmaAldrich, St Louis, USA) supplemented with 10\% fetal bovine serum (FBS; Gibco, Grand Island, NY, USA), 100 units antibiotic/antimycotic solution (Invitrogen, Carlsbad, CA, USA) and $50 \mu \mathrm{g} / \mathrm{mL}$ gentamycin (Invitrogen) with $1 \mathrm{mM}$ Na pyruvate at $37^{\circ} \mathrm{C}$ in a humidified atmosphere with $5 \% \mathrm{CO}_{2}$.

Cell treatment and plasmid transfection

Mature miR-194 mimic and miR-194 inhibitor were designed and synthesized by GenePharma (Shanghai, China). Cells without any vector transfection were regarded as the control group. Briefly, the cells $\left(1 \times 10^{5}\right.$ cells/per well) were seeded on 96-well plates for $12 \mathrm{~h}$ and then were transiently transfected with 20 nM miR-194 mimic or miR-194 inhibitor following the manufacturer's instruction by Lipofectamine 2000 (Invitrogen) for $48 \mathrm{~h}$. The detailed sequences were listed as following: miR-194 mimic sense 5'-UGUAACAGCAAC UCCAUGUGGA-3' and mimic antisense 5'-CACAUGGAGUUGCUGUUACAUU-3'. miR-194 
inhibitor 5'-UCCACAUGGAGUUGCUGUUACA-3'. The transfection efficiency was confirmed by quantitative real-time polymerase chain reaction (qRT-PCR). The cells were then treated with or without $10 \mu \mathrm{g} / \mathrm{ml}$ E.coli-derived LPS (026:B6, Sigma-Aldrich) after plasmid transfection. The cell suspension was collected for further analyses.

qRT-PCR

Total RNA, including miRNA, was isolated from the transfected and treated cells by using miRNeasy Mini Kit (Qiagen, Valencia, CA, USA) according to the manufacturer's protocol. Reverse transcription was carried out using Multiscribe RT kit (Applied Biosystems, Foster City, CA, USA). The reverse transcription conditions were set at $30 \mathrm{~min}$ at $25^{\circ} \mathrm{C}, 30 \mathrm{~min}$ at $42^{\circ} \mathrm{C}, 5 \mathrm{~min}$ at $85^{\circ} \mathrm{C}$, and a termination reaction at $4^{\circ} \mathrm{C}$. The sequences of the primers were as follows: miR-194 forward primer: 5'-GCCCGCTGTAACAGCAACTCCAT-'3, reverse primer: 5'-GTGCAGGGTCCGAGGT-'3; U6 forward primer: 5'-CTCGCTTCGGC AGCACA-3', reverse primer: 5'-CTCGCTTCGGCAGCACA-3'; IкB $\alpha$ forward primer: 5'-CGGGTTCCTGCACTTGGCCATC-3', reverse primer: 5'-GTCCGGCCATTACAGGG CTC-3'; p65 forward primer: 5'-CTTAAGGAAAATTGAGGGAGGGCACGC-3', reverse primer: 5'-TGACTCAGTTTCCCTCCACACCGTCC-3'; Bcl-3 forward primer: 5'-CACGA AGGTTCCCTCTCTGGAAT-3', reverse primer: 5'-TGATCAATGTCCTCCCAATCCC-3'; and GAPDH forward primer: 5'-CTCGCTTCGGCAGCACA-3', reverse primer: 5'-AACGCTTCACGAATTTGCGT-3'. All reactions were performed in triplicate and the data were analyzed by $2^{-\Delta \Delta C}{ }_{T}$ method.

\section{Cell viability}

After incubation with LPS and/or transfection with miR-194 mimic or miR-194 inhibitor, the cell viability was analyzed by 3-(4, 5-dimethylthiazol-2-yl)-2 5-diphenyl-2Htetrazolium bromide (MTT) colorimetric assay according to a standardized method [17]. Briefly, the cells were seeded in 96-well plates and treated with LPS and/or transfected with miR-194 mimic or miR-194 inhibitor. After 1, 2, 3, and 4 days of treatment, $20 \mu \mathrm{L} 5 \mathrm{mg} / \mathrm{mL}$ MTT (Invitrogen) was added to the plates and incubated at $37^{\circ} \mathrm{C}$ for $4 \mathrm{~h}$. Thereafter, $100 \mu \mathrm{L}$ dimethylsulfoxide (DMSO; Sigma-Aldrich) was added to dissolve the formazan crystals. Absorbance at $570 \mathrm{~nm}$ was read by a microplate reader (Bio-Rad Benchmark, Hercules, CA, USA). The data was graphed as relative cell viabilities [(OD570 drug)/ (OD570 virus control)] for each group.

\section{Apoptosis assay}

After incubation with LPS and/or transfection with miR-194 mimic or miR-194 inhibitor, the cell apoptosis was assessed by an Annexin V/ fluorescein isothiocynate (FITC) and propidium iodide (PI) apoptosis detection kit (BD Biosciences, Heidelberg, Germany) according to the manufacturer's criterions. Briefly, after treatment and transfection for $48 \mathrm{~h}$, the cells were harvested and suspended in Annexin-binding buffer, and then were incubated with Annexin V-FITC and PI for $15 \mathrm{~min}$ in the dark at room temperature. The apoptotic percentages of cells were analyzed by flow cytometry using a FACScan cytometer (BD Biosciences, USA) and the data was analyzed with FlowJo software (Tree Star, Ashland, OR).

\section{Western blot analysis}

After incubation with LPS and/or transfection with miR-194 mimic, the cell suspension was collected, centrifuged, and lysed in a RIPA lysis buffer containing protease inhibitor. The proteins were quantified using the BCA $\mathrm{A}^{\mathrm{TM}}$ Protein Assay Kit (Pierce, Rockford, IL). The protein samples were then subjected to a 10-12\% sodium dodecyl sulfate (SDS)-polyacrylamide gel electrophoresis (PAGE) gels and transferred to polyvinylidene fluoride (PVDF) membranes. After washing with phosphate buffer saline (PBS), the membranes were then blocked with 5\% skim milk in Tris Buffered Saline with Tween (TBST) for $1 \mathrm{~h}$. Subsequently, the membranes were incubated with the following primary antibodies overnight at $4^{\circ} \mathrm{C}$ : anti-IкB $\alpha$ antibody (rabbit mAb \#4812; Cell Signaling Technology, Beverly, MA, USA); anti-phosphoI $\mathrm{B} \alpha(\mathrm{p}-\mathrm{I} \kappa \mathrm{B} \alpha)$ antibody (rabbit mAb \#5209; Cell Signaling Technology); anti-p65 antibody (rabbit mAb \#8242; Cell Signaling Technology); anti-phospho-p65 (p-p65) antibody (rabbit mAb \#3033; Cell Signaling Technology); and anti-B-cell CLL/lymphoma 3 (Bcl-3) antibody (rabbit mAb ab137499, Abcam, Cambridge, UK). The membranes were then washed three times with TBST and incubated with horseradish peroxidase (HRP)-conjugated secondary antibodies (Abcam) for $2 \mathrm{~h}$. WEST-ZOL-plus Western Blot Detection System (Intron Biotechnology, Inc., Korea) was used to detect the protein bands. Probing for GAPDH (Abcam) was used as a loading control. 
Statistical analysis

Each experiment was run in triplicate. The data was expressed as mean \pm standard deviation (SD). All statistical analyses were performed with Statistic Package for Social Science (SPSS, version 19.0, SPSS Inc., Chicago, Illinois, USA) statistical software. One-way analysis of variance (ANOVA) was performed to calculate the P-values. A $P$-value of $<0.05$ was considered statistically significant.

\section{Results}

\section{Transfection efficiency of miR-194}

qRT-PCR was performed to confirm the transfection efficiency. As shown in Fig. 1A, the expression levels of miR-194 were significantly increased by transfection with miR-194 mimic compared to the control group $(P<0.01)$, and were statistically decreased by transfection with miR-194 inhibitor $(P<0.05)$. The results demonstrated that the transfection efficiency was apparent and could be used for further analysis.

\section{Effects of miR-194 aberrant expression on cell viability}

After abnormal expression of miR-194, we analyzed the effects of miR-194 aberrant expression on cell viability. The cell viability was determined by MTT. As shown in Fig. $1 \mathrm{~B}$, the results revealed that the cell viability was greatly lowered by LPS compared to the control group after 3 and 4 days of treatment (both $P<0.01$ ). No significant differences were found in the cell viability after 1 and 2 days of treatment. In addition, we observed that LPS combined with overexpression of miR-194 prominently elevated the cell viability compared to the LPS group after 3 and 4 days of treatment $(P<0.05$ or $P<0.01)$, and while suppression of miR-194 remarkably downregulated the cell viability compared to the LPS group after 3 and 4 days of treatment (both $P<0.05$ ). The results indicated that overexpression of miR194 could significantly promote the cell viability.

\section{Effects of miR-194 aberrant expression on cell apoptosis}

Moreover, the effects of miR-194 aberrant expression on the cell apoptosis were analyzed by flow cytometry. As shown in Fig. 2A and 2B, we found that compared to the control group, the percentages of apoptotic cells were remarkably promoted by LPS $(P<0.05)$. However, the percentages of apoptotic cells were strikingly downregulated by overexpression of miR-194

Fig. 1. (A) Transfection efficiency of miR-194. Human fibroblasts WI38 cells were transfected with miR-194 mimic or miR-194 inhibitor, and the transfection efficiency was confirmed by qRT-PCR. The re-

A

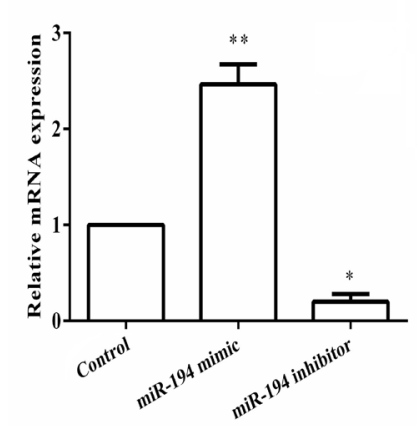

B

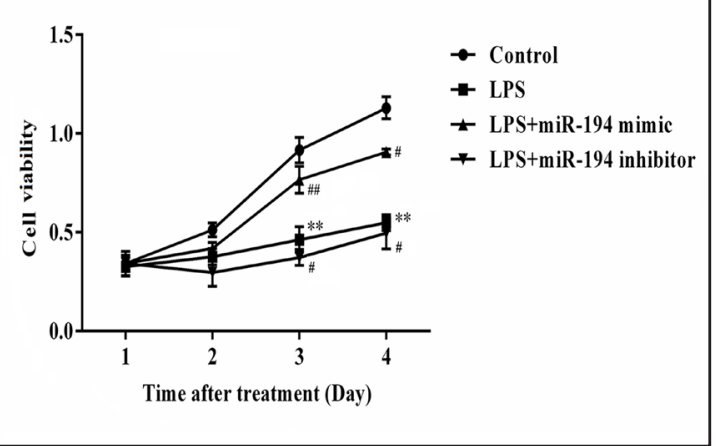
sults indicated high transfection efficiency. (B) Effects of miR-194 aberrant expression on cell viability. The effects of miR-194 aberrant expression on cell viability were analyzed by MTT. The results showed that overexpression of miR-194 could dramatically increase the cell viability that was lowered by LPS at 3 and 4 days. Suppression of miR-194 further decreased the cell viability induced by LPS. MiR, microRNA; MTT, 3-(4, 5-dimethylthiazol-2-yl)-2 5-diphenyl-2Htetrazolium bromide; LPS, lipopolysaccharide. ${ }^{* *} \mathrm{P}<0.01$ compared to the control group; ${ }^{\#} \mathrm{P}<0.05$ compared to the LPS group; ${ }^{\# \#} \mathrm{P}<0.01$ compared to the LPS group. 
Fig. 2. Effects of miR-194 aberrant expression on cell apoptosis. The effects of miR-194 aberrant expression on cell apoptosis were determined by flow cytometry. The Figure 3 (A) and (B) showed that overexpression of miR-194 could statistically decrease the cell apoptosis that was upregulated by LPS. Suppression of miR-194 further elevated the cell apoptosis induced by LPS. MiR, microRNA; LPS, lipopolysaccharide. ${ }^{*} P<0.05$ compared to the control group; ${ }^{\#} P<0.05$ compared to the LPS group.

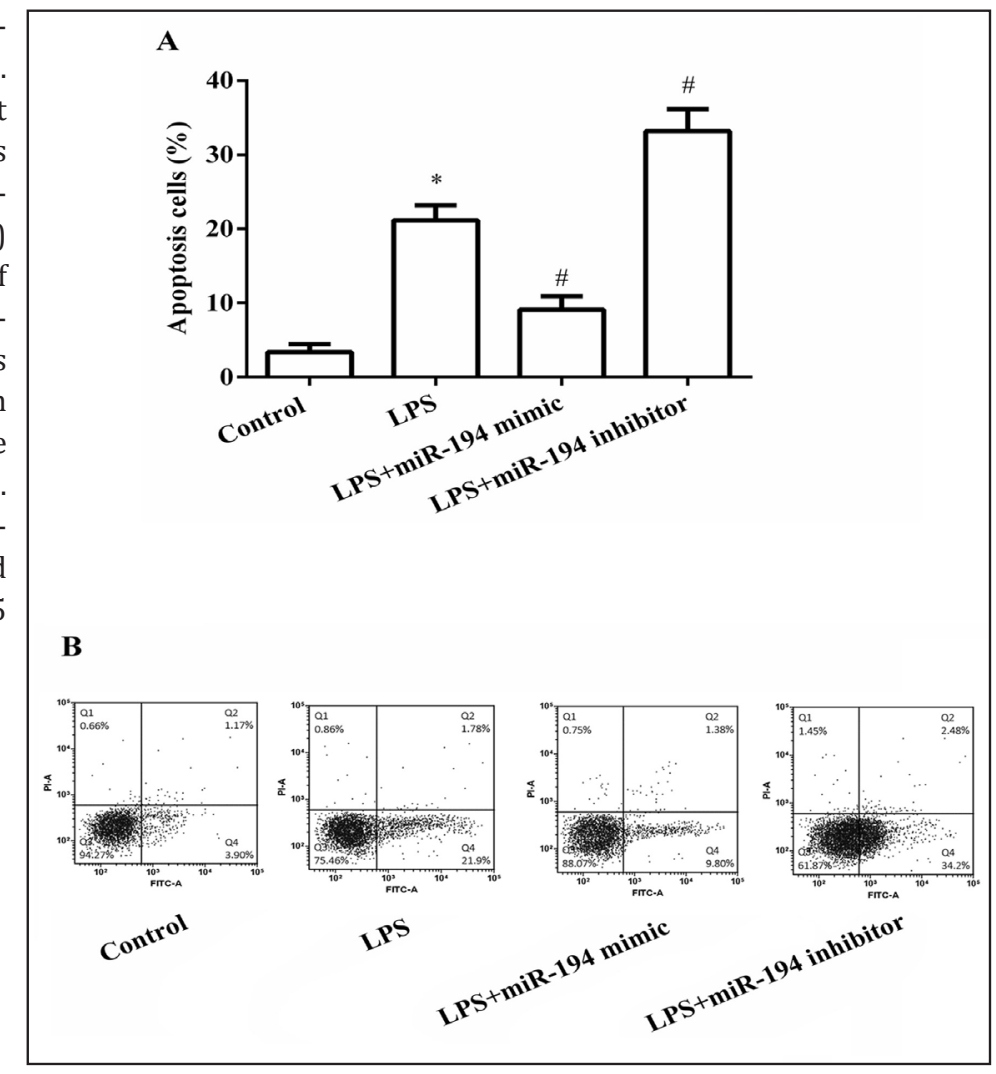

Fig. 3. Effects of miR-194 overexpression on the NF- $\mathrm{B}$ pathway key proteins expression. The effects of miR-194 overexpression on the NF- $\mathrm{B}$ pathway key proteins expression were measured by qRT-PCR and Western blot. (A) mRNA expressions of $\mathrm{p} / \mathrm{t}-\mathrm{I} \kappa \mathrm{B} \alpha, \mathrm{p} / \mathrm{t}-\mathrm{p} 65$, and $\mathrm{Bcl}-3$; (B), protein expressions of $\mathrm{p} / \mathrm{t}$ $\mathrm{I} \kappa \mathrm{B} \alpha, \mathrm{p} / \mathrm{t}-\mathrm{p} 65$, and $\mathrm{Bcl}-3$. MiR, microRNA; LPS, lipopolysaccharide; $N F-\kappa B$, nuclear factor kappa $B$; IкB, inhibitor of NF- $\kappa B$; $\mathrm{Bcl}$, B-cell CLL/lymphoma; qRTPCR, quantitative real time polymerase chain reaction. ${ }^{*} \mathrm{P}<0.05$ compared to the control group; \# $\mathrm{P}<0.05$ compared to the LPS group; ${ }^{\# \#} \mathrm{P}<0.01$ compared to the LPS group.

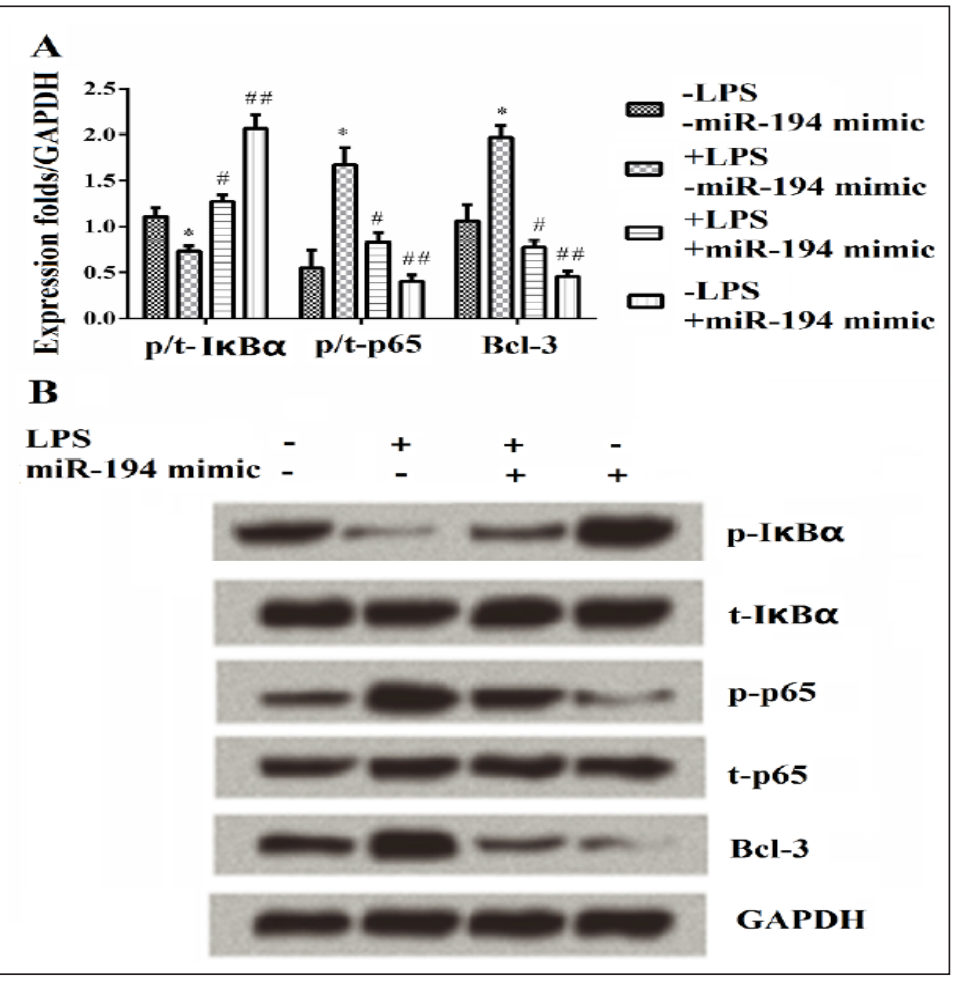

compared to the LPS group $(P<0.05)$, and while were distinctly increased by suppression of miR-194 $(P<0.05)$. These data suggested that overexpression of miR-194 could statistically inhibit the cell apoptosis.

\section{KARGER}




\section{Cellular Physiology Cell Physiol Biochem 2017;43:2470-2478

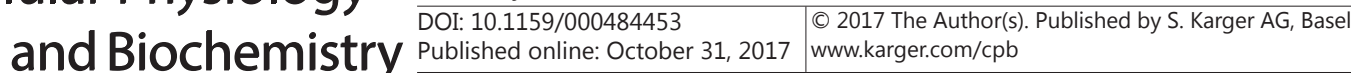 \\ Xie et al.: Potential Role of Mir-194 in Pneumonia}

Effects of miR-194 overexpression on the NF- $\kappa B$ pathway key proteins expression

To further understand the underlying mechanism, both mRNA and protein expressions of NF- $\kappa B$ pathway key proteins, I $\kappa \mathrm{B} \alpha, \mathrm{p}-\mathrm{I} \kappa \mathrm{B} \alpha, \mathrm{p}-65, \mathrm{p}-\mathrm{p} 65$, and $\mathrm{Bcl}-3$, were measured after miR-194 aberrant expression and/or treatment with LPS. Non-treated cells were considered as the control group. As indicated in Fig. 3A, the data showed that the mRNA expression levels of $\mathrm{p} / \mathrm{t}-\mathrm{p} 65$ and $\mathrm{Bcl}-3$ were all significantly raised but the levels of $\mathrm{p} / \mathrm{t}-\mathrm{I} \kappa \mathrm{B} \alpha$ were lowered by LPS compared to the control group $(P<0.05)$. Moreover, LPS combined with overexpression of miR-194 statistically reversed the effects of LPS $(P<0.05)$, while on the other hand, miR194 overexpression alone further statistically increased the mRNA levels of $\mathrm{p} / \mathrm{t}-\mathrm{I \kappa} \mathrm{B} \alpha$ but decreased levels of $\mathrm{p} / \mathrm{t}-\mathrm{p} 65$ and Bcl-3 compared to the LPS group $(P<0.01)$. Similar results were observed in the protein levels (Fig. 3B). Our results indicated that overexpression of miR-194 could inhibit the NF- $\kappa$ B pathway.

\section{Discussion}

In the present study, the results showed that LPS significantly downregulated the cell viability, upregulated the percentages of apoptotic cells, increased the mRNA and protein expressions of p-65 and Bcl-3 but decreased expression of I $\mathrm{I} B \alpha$. Overexpression of miR194 significantly attenuated the effects of LPS on cell viability, cell apoptosis, and the mRNA and protein expressions of I $\mathrm{K} \mathrm{B} \alpha, \mathrm{p}-65$, and Bcl-3. However, suppression of miR-194 further enhanced the effects of LPS on cell viability and cell apoptosis. Our study indicated that miR194 might be a protective factor in LPS-induced lung injury and overexpression of miR-194 might be a potential targeted therapy for treatment of infantile pneumonia.

The functional role of miR-194 has been studied for a long time; however, most studies have been focused on its biological functions in various tumour cells. Emerging studies suggest that miR-194 is considered as a tumour suppressor and its targets were identified in many cells and tissues. For example, Han et al. demonstrated that overexpression of miR194 significantly repressed the proliferation, migration, and invasion of osteosarcoma cells in vitro, as well as tumour growth and pulmonary metastasis in vivo by targeting cadherin-2 (CDH2) and insulin-like growth factor 1 receptor (IGF-1R) [12]. In addition, it has been reported that miR-194 inhibited the EMT of EC cells [14] and gastric cancer cells [18]. MiR194 has been identified as a prognostic marker of clear cell renal cell carcinoma (ccRCC) [19], myelodysplastic syndromes (MDS) [20], and HCC [15]. In addition to cancers, the biological functions of miR-194 in other diseases such as diabetes [21] and postmenopausal osteoporosis have also been investigated [22]. More recently, a study demonstrated that miR-194 was related with inflammatory response induced by palmitic acid (PA) [23]. In consideration of the above effects, we speculated that miR-194 might be involved in lung cell inflammatory response.

To confirm the hypothesis, the expression of miR-194 was first aberrantly expressed in human lung fibroblast WI38 cells by transfection with miR-194 mimic or inhibitor. After determining the high efficiency, we administrated LPS to the cells. LPS is a critical structural component of the outer membrane of Gram-negative bacteria, leading to systemic inflammatory response and nonspecific immune responses [24]. LPS is a widely used proinflammatory agent and is commonly accepted as a model of inducing pneumonia. The cell viability and the cell apoptosis were then measured after aberrant expression of miR194 and administration of LPS. As expected, LPS significantly decreased the cell ability and increased the percentages of apoptotic cells compared to the control group, indicating a successful model for lung cell injury. Unlike the biological function of miR-194 in tumour cells, our study suggested that overexpression of miR-194 enhanced the cell viability and inhibited the cell apoptosis. But our study had similarities with those previous studies that miR-194 acted as a protective factor against diseases.

To further explore the underlying signalling pathway related to the effects of miR-194 aberrant expression on the cell viability and the cell apoptosis, we measured key proteins in 
NF- $\kappa$ B pathway including I $\kappa \mathrm{B} \alpha, \mathrm{p}-65$, and Bcl-3. Activation of the NF- $\kappa \mathrm{B}$ signalling pathway plays a critical role in many different cell functions, such as inflammation, oncogenesis, cell apoptosis, and cell cycle progression [25]. Previous studies have demonstrated that LPS could induce the release of inflammatory cytokines and active NF- $\kappa B$ pathway [26-28]. $\mathrm{I} \kappa \mathrm{B} \alpha$, a crucial negative regulator of NF- $\kappa \mathrm{B}$ activation, binds to NF- $\kappa \mathrm{B}$, which blocks it in the cytoplasm and inhibits DNA binding [29]. Bcl-3, one of novel or atypical IкB-like proteins, is also responsible for the activation of NF- $\kappa B$ pathway. However, the functional role of Bcl-3 in activation of NF- $\kappa B$ pathway is controversial. A few studies suggest that Bcl-3 participates in the removal of p50 and p52 homodimers from DNA and thus inhibits the transcriptional repressive effects of transcription activation domain (TAD) [30-32]. In contrast, other studies point that Bcl-3 interacts with p52 and p50, conferring upon them transcriptional activity [33-36]. p65, a subunit of NF- $\kappa B$, which is released from cytosolic I $\kappa \mathrm{B} \alpha$ and targeted to the nucleus after phosphorylation and ubiquitination of I $\mathrm{B} \alpha$ [37]. Our results revealed that LPS

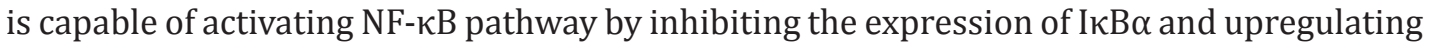
the expression of $\mathrm{p} 65$ and Bcl-3. In contrast, overexpression of miR-194 reversed the effects of LPS on key proteins expressions, leading to inactivation of NF- $\mathrm{B}$ pathway.

\section{Conclusion}

Our results suggest that miR-194 functions as a protective factor in LPS induced lung cell injury by increasing lung cell viability and inhibiting cell apoptosis. These effects might be achieved by inhibition of NF- $\kappa$ B pathway in WI38 cells. Additionally, miR-194 overexpression might be a potentially effective treatment of infantile pneumonia.

\section{Abbreviations}

LPS (lipopolysaccharide); miRNAs (microRNAs); CDH2 (cadherin-2); IGF-1R (insulin-like growth factor 1 receptor); EMT (epithelial-mesenchmal transition); MDS (myelodysplastic syndromes); HCC (hepatocellular carcinoma); PA (palmitic acid); TAD (transcription activation domain).

\section{Acknowledgements}

FX, LY analysed the data and wrote the manuscript; FX, LY, LLH performed genotyping and analysed the data; BY performed computational analysis; All authors read and approved the final manuscript.

This research received no specific grant from any funding agency in the public, commercial or not-for-profit sectors.

\section{Disclosure Statement}

The authors declare that they have no competing interests.

\section{References}

1 Chen CH, Wen HJ, Chen PC, Lin SJ, Chiang TL, Hsieh IC, Guo YL: Prenatal and postnatal risk factors for infantile pneumonia in a representative birth cohort. Epidemiol Infect 2012;140:1277-1285.

2 Juan W, Han Z, Chunfeng L: Three cases of children severe mycoplasma pneumonia combined with acute respiratory distress syndrome. Chin. Pediatric Emergency Medi 2011;18:475-476. 


\section{Cellular Physiology Cell Physiol Biochem 2017;43:2470-2478 and Biochemistry Published \begin{tabular}{l|l} 
DOI: 10.1159/000484453 & $\begin{array}{l}\text { C } 2017 \text { The Author(s). Published by S. Karger AG, Basel } \\
\text { www.karger.com/cpb }\end{array}$
\end{tabular} \\ Xie et al.: Potential Role of Mir-194 in Pneumonia}

3 Yang F: Oxygen-driving and atomized mucosolvan inhalation combined with holistic nursing in the treatment of children severe bronchial pneumonia. Pak J Pharm Sci 2015;28:1477-1480.

4 Shukla GC, Singh J, Barik S: MicroRNAs: Processing, Maturation, Target Recognition and Regulatory Functions. Mol Cell Pharmacol 2011;3:83-92.

5 Bartel DP: MicroRNAs: target recognition and regulatory functions. Cell 2009;136:215-233.

6 Bartel DP: MicroRNAs: genomics, biogenesis, mechanism, and function. Cell 2004;116:281-297.

7 Abd-El-Fattah AA, Sadik NA, Shaker OG, Aboulftouh ML: Differential microRNAs expression in serum of patients with lung cancer, pulmonary tuberculosis, and pneumonia. Cell Biochem Biophys 2013;67:875884.

8 Bhan U, Podsaid A, Ballinger MN, Domingo RG, Moore BB, Standiford TJ: Post Viral Bacterial Pneumonia: Role Of MicroRNA. Am J Respir Crit Care Med 187 2013:A55489.

9 Griss K, Han M, Nell C, Bertrams W, Seidel K, Klemmer A, Sittka A, Hippenstiel S, Schmeck B: microRNAs as biomarkers in pneumonia and COPD-exacerbation - the Bioinflame study. Pneumologie 2015;69:42-49.

10 Hino K, Tsuchiya K, Fukao T, Kiga K, Okamoto R, Kanai T, Watanabe M: Inducible expression of microRNA-194 is regulated by HNF-1 $\alpha$ during intestinal epithelial cell differentiation. RNA 2008;14:14331442.

11 Le XF, Almeida MI, Mao W, Spizzo R, Rossi S, Nicoloso MS, Zhang S, Wu Y, Calin GA, Bast RC, Jr.: Modulation of MicroRNA-194 and cell migration by HER2-targeting trastuzumab in breast cancer. PLoS One 2012;7:e41170.

12 Han K, Zhao T, Chen X, Bian N, Yang T, Ma Q, Cai C, Fan Q, Zhou Y, Ma B: microRNA-194 suppresses osteosarcoma cell proliferation and metastasis in vitro and in vivo by targeting CDH2 and IGF1R. Int J Oncol 2014;45:1437-1449.

13 Song Y, Feng Z, Wang Z, Liu Z, Chiang Y, Xu Y, Peng G, Xu H: Inverse Association between miR-194 Expression and Tumor Invasion in Gastric Cancer. Ann Surg Oncol 2012;19:509-517.

14 Dong P, Kaneuchi M, Watari H, Hamada J, Sudo S, Ju J, Sakuragi N: MicroRNA-194 inhibits epithelial to mesenchymal transition of endometrial cancer cells by targeting oncogene BMI-1. Mol Cancer 2011;10:99.

15 Zhao Y, Li F, Zhang X, Liu A, Qi J, Cui H, Zhao P: MicroRNA-194 acts as a prognostic marker and inhibits proliferation in hepatocellular carcinoma by targeting MAP4K4. Int J Clin Exp Pathol 2015;8:12446-12454.

16 Xu J, Kang Y, Liao WM, Yu L: MiR-194 regulates chondrogenic differentiation of human adipose-derived stem cells by targeting Sox5. PLoS One 2012;7:e31861.

17 Inada T, Kubo K, Shingu K: Possible link between cyclooxygenase-inhibiting and antitumor properties of propofol. J Anesth 2011;25:569-575.

18 Li Z, Ying X, Chen H, Ye P, Shen Y, Pan W, Zhang L: MicroRNA-194 Inhibits the Epithelial-Mesenchymal Transition in Gastric Cancer Cells by Targeting FoxM1. Dig Dis Sci 2014;59:2145-2152.

19 Nofech-Mozes R, Khella HW, Scorilas A, Youssef L, Krylov SN, Lianidou E, Sidiropoulos KG, Gabril M, Evans A, Yousef GM: MicroRNA-194 is a Marker for Good Prognosis in Clear Cell Renal Cell Carcinoma. Cancer Med 2016;5:656-664.

20 Choi JS, Nam MH, Yoon SY, Kang SH: MicroRNA-194-5p could serve as a diagnostic and prognostic biomarker in myelodysplastic syndromes. Leuk Res 2015;39:763-768.

-21 Celine L, Alaina N, Medini RL, Heywood SE, Armitage JA, Kingwell BA: MicroRNA-194 Modulates Glucose Metabolism and Its Skeletal Muscle Expression Is Reduced in Diabetes. PLoS One 2016;11:e0155108.

-22 Meng J, Zhang D, Pan N, Sun N, Wang Q, Fan J, Zhou P, Zhu W, Jiang L: Identification of miR-194-5p as a potential biomarker for postmenopausal osteoporosis. Peerj 2015;3:e971.

-23 Tian H, Liu C, Zou X, Wu W, Zhang C, Yuan D: MiRNA-194 Regulates Palmitic Acid-Induced Toll-Like Receptor 4 Inflammatory Responses in THP-1 Cells. Nutrients 2015;7:3483-3496.

24 Lu YC, Yeh WC, Ohashi PS: LPS/TLR4 signal transduction pathway. Cytokine 2008;42:145-151.

25 Chen F, Demers LM, Shi X: Upstream signal transduction of NF-kappaB activation. Curr Drug Targets Inflamm Allergy 2002;1:137-149.

-26 Faure E, Equils O, Sieling PA, Thomas L, Zhang FX, Kirschning CJ, Polentarutti N, Muzio M, Arditi M: Bacterial lipopolysaccharide activates NF-kappaB through toll-like receptor 4 (TLR-4) in cultured human dermal endothelial cells. Differential expression of TLR-4 and TLR-2 in endothelial cells. J Biol Chem 2000;275:11058-11063.

27 Zhang G, Ghosh S: Molecular mechanisms of NF- $\mathrm{kB}$ activation induced by bacterial lipopolysaccharide through Toll-like receptors. J Endotoxin Res 2000;6:453-457. 


\section{Cellular Physiology Cell Physiol Biochem 2017;43:2470-2478

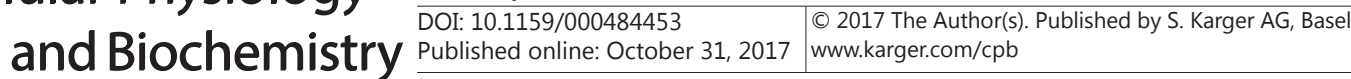 \\ Xie et al.: Potential Role of Mir-194 in Pneumonia}

28 Frede S, Stockmann C, Freitag P, Fandrey J: Bacterial lipopolysaccharide induces HIF-1 activation in human monocytes via p44/42 MAPK and NF-кB. Biochem J 2006;396:517-527.

29 Fujihara S, Jaffray E, Farrow SN, Rossi AG, Haslett C, Hay RT: Inhibition of NF- $\kappa$ B by a cell permeable form of IкB $\alpha$ induces apoptosis in eosinophils. Biochem Biophys Res Commun 2005;326:632-637.

-30 Naumann M, Wulczyn FG, Scheidereit C: The NF-kappa B precursor p105 and the proto-oncogene product Bcl-3 are I kappa B molecules and control nuclear translocation of NF-kappa B. EMBO J 1993;12:213-222.

31 Franzoso G, Bours V, Azarenko V, Park S, Tomitayamaguchi M, Kanno T, Brown K, Siebenlist U: The oncoprotein Bcl-3 can facilitate NF-kappa B-mediated transactivation by removing inhibiting p50 homodimers from select kappa B sites. EMBO J 1993;12:3893-3901.

32 Hatada EN, Nieters A, Wulczyn FG, Naumann M, Meyer R, Nucifora G, Mckeithan TW, Scheidereit C: The ankyrin repeat domains of the NF- $\mathrm{BB}$ precursor p105 and the protooncogene bcl-3 act as specific inhibitors of NF-kB DNA binding. Proc Natl Acad Sci U S A 1992;89:2489-2493.

33 Bours V, Franzoso G, Azarenko V, Park S, Kanno T, Brown K, Siebenlist U: The oncoprotein Bcl-3 directly transactivates through $\mathrm{\kappa B}$ motifs via association with DNA-binding p50B homodimers. Cell 1993;72:729739.

34 Fujita T, Nolan GP, Liou HC, Scott ML, Baltimore D: The candidate proto-oncogene bcl-3 encodes a transcriptional coactivator that activates through NF-kappa B p50 homodimers. Genes Dev 1993;7:13541363.

-35 Caamaño JH, Perez P, Lira SA, Bravo R: Constitutive expression of Bc1-3 in thymocytes increases the DNA binding of NF-kappaB1 (p50) homodimers in vivo. Mol Cell Biol 1996;16:1342-1348.

-36 Chang CC, Zhang J, Lombardi L, Neri A, Dallafavera R: Rearranged NFKB-2 genes in lymphoid neoplasms code for constitutively active nuclear transactivators. Mol Cell Biol 1995;15:5180-5187.

37 Chen ZJ: Ubiquitin signalling in the NF-kappaB pathway. Nat Cell Biol 2005;7:758-765. 